Article

\title{
The Potential of a Nanostructured Titanium Oxide Layer with Self-Assembled Monolayers for Biomedical Applications: Surface Properties and Biomechanical Behaviors
}

\author{
Wen-Chien Lan ${ }^{1}$, Ta-Sen Huang ${ }^{2,+}$, Yung-Chieh Cho ${ }^{3}$, Yueh-Tzu Huang ${ }^{4}$, \\ Christopher J. Walinski ${ }^{5}$, Pao-Chang Chiang ${ }^{3,6}$, Muhammad Rusilin ${ }^{7}$, Fang-Tzu Pai ${ }^{8}$, \\ Chien-Chia Huang ${ }^{9, *}$ and Mao-Suan Huang ${ }^{2,10, *}$ \\ 1 Department of Oral Hygiene Care, Ching Kuo Institute of Management and Health, Keelung 203, Taiwan; \\ jameslan@ems.cku.edu.tw \\ 2 Department of Dentistry, Taipei Medical University-Shuang Ho Hospital, New Taipei City 235, Taiwan; \\ frogyellow7788@yahoo.com.tw \\ 3 School of Dentistry, College of Oral Medicine, Taipei Medical University, Taipei 110, Taiwan; \\ D204106003@tmu.edu.tw (Y.-C.C.); m204095009@tmu.edu.tw (P.-C.C.) \\ 4 Division of Family and Operative Dentistry, Department of Dentistry, Taipei Medical University Hospital, \\ Taipei 110, Taiwan; yeahmeow2@gmail.com \\ 5 Department of Restorative Dentistry, Health Science Center, College of Dentistry, University of Tennessee, \\ Tennessee, TN 38163, USA; cwalinsk@uthsc.edu \\ 6 Dental Department of Wan-Fang Hospital, Taipei Medical University, Taipei 116, Taiwan \\ 7 Department of Oral and Maxillofacial Surgery, Faculty of Dentistry, Hasanuddin University, Makassar 90245, \\ Indonesia; ruslin_oms@yahoo.com \\ 8 School of Dental Technology, Taipei Medical University, Taipei 110, Taiwan; M249108004@tmu.edu.tw \\ 9 School of Dentistry, Health Sciences University of Hokkaido, Hokkaido 061-0293, Japan \\ 10 School of Oral Hygiene, College of Oral Medicine, Taipei Medical University, Taipei 110, Taiwan \\ * Correspondence: courageev@hotmail.com (C.-C.H.); hms4837@tmu.edu.tw (M.-S.H.) \\ + Co-First author: Ta-Sen Huang.
}

Received: 21 November 2019; Accepted: 6 January 2020; Published: 14 January 2020

\begin{abstract}
This study investigated the surface properties and biomechanical behaviors of a nanostructured titanium oxide (TiO) layer with different self-assembled monolayers (SAMs) of phosphonate on the surface of microscope slides. The surface properties of SAMs were analyzed using scanning electron microscopy, X-ray photoemission spectroscopy, and contact angle goniometry. Biomechanical behaviors were evaluated using nanoindentation with a diamond Berkovich indenter. Analytical results indicated that the homogenous nanostructured TiO surface was formed on the substrate surface after the plasma oxidation treatment. As the TiO surface was immersed with 11-phosphonoundecanoic acid solution (PUA-SAM/TiO), the formation of a uniform SAM can be observed on the sample surface. Moreover, the binding energy of $\mathrm{O} 1 \mathrm{~s}$ demonstrated the presence of the bisphosphonate monolayer on the SAMs-coated samples. It was also found that the PUA-SAM/TiO sample not only possessed a higher wettability performance, but also exhibited low surface contact stiffness. A SAM surface with a high wettability and low contact stiffness could potentially promote biocompatibility and prevent the formation of a stress shielding effect. Therefore, the self-assembled technology is a promising approach that can be applied to the surface modification of biomedical implants for facilitating bone healing and osseointegration.
\end{abstract}

Keywords: titanium oxide; self-assembled monolayer; wettability; nanoindentation 


\section{Introduction}

Pure titanium (Ti) is one of the most common metallic biomaterials that has been used in artificial implants owing to its favorable mechanical properties, anti-corrosion performances, excellent biocompatibility, and so on [1-5]. However, there are still some drawbacks from Ti implants that should be considered for improvement, such as the native oxide on Ti being bioinert, which only physically contacts with bone tissue, and the mismatch in Young's modulus between the Ti implant (70-110 GPa) and alveolar bone tissue (3-40 GPa) [6,7]. The mismatch in Young's modulus leads to the formation of stress shielding, and bone resorption and loss, as well as poor in vivo osseointegration. Moreover, the surface characteristics of a Ti implant will affect the resulting cell adhesion, proliferation, differentiation, and active-matrix remodeling behaviors [8-11]. In order to improve these drawbacks, numerous studies have been done to create functionalized surfaces on Ti implants through different surface modification methods [9,12-14]. It is well known that sand-blasting or plasma spraying method is applied to increase the surface roughness of Ti implants [15,16]. An appropriate surface roughness results in an improved mechanical interlock between the Ti implant and bone tissue [17,18]. For chemical etching, alkaline treatment, and chemical deposition methods, many reports have demonstrated that the surface morphology and chemical composition of Ti implants could be modified effectively $[19,20]$. Thus, these kinds of surface modification methods were adopted to alter the physical and chemical properties of Ti surface in the present study.

Recently, our research team has focused on developing a novel and efficient method to immobilize biomolecules on the Ti oxide (TiO) layer [14] to attract cells of the host tissue, which then produce their own extracellular matrix and actively remodel the environment. However, we also found that using a self-assembled monolayer (SAM) is a promising method that can be used to immobilize the molecular chain on materials for fabricating surfaces with highly controlled chemical properties [21-23]. SAMs have been applied in industrial fields, such as to protect metal from corrosion, promote coating adhesion, enhance lubrication, lithography resists and photonic devices, etc. Nevertheless, there is a great idea of interest in forming SAMs of phosphonate on the surface of a metal oxide layer using alkyl phosphate and phosphonic acid solutions as appropriate anchor groups for biomedical applications [24-26]. The SAM plays an important role in modifying the surface properties of Ti. Based on the improvement of Ti implants, the purpose of the present study was to fabricate the biocompatible SAMs on a TiO layer using four kinds of phosphonic acid solutions via self-assembly technology and investigate their surface properties and biomechanical behaviors. The research findings could provide new scientific information in the dentistry fields.

\section{Materials and Methods}

\subsection{Substrata}

Microscope slides with a thickness of $1 \mathrm{~mm}$ were used as the substrata in this study. The substrata were prepared as a square with dimensions of $10 \mathrm{~mm} \times 10 \mathrm{~mm}$. Before the surface treatment, the glass substrata were ultrasonically cleaned according to the sequence of acetone (30 $\mathrm{min})$, ethanol (30 $\mathrm{min})$, and distilled water $(30 \mathrm{~min})$, and then dried thoroughly in an electric drying oven at $30^{\circ} \mathrm{C}$.

\subsection{Preparation of SAMs on the Nanostructured TiO layer}

The radio-frequency plasma (13.56 MHz generator) combined with a magnetron sputtering (Ti target, $99.99 \%$ purity) system was employed to deposit the TiO film on the microscope slides at $1 \mathrm{~kW}$ for $30 \mathrm{~min}$ under a chamber running pressure of $5.0 \times 10^{-3}$ Torr, oxygen flow rate of $30 \mathrm{sccm}$, and temperature of $25^{\circ} \mathrm{C}$ ( $\mathrm{TiO}$ is an inorganic chemical compound of Ti and $\mathrm{O}$, which can be formed on a Ti metal surface through the plasma ion bombardment method [27]; the plasma exothermic reaction provides a vital driving force for the transport of $\mathrm{O}$ species at lattice or interstitial sites to form the $\mathrm{TiO} / \mathrm{Ti}$ ). After the deposition process, the $\mathrm{TiO}$-coated samples were ultrasonically cleaned according to the sequence of ethanol $(10 \mathrm{~min})$ and distilled water $(10 \mathrm{~min})$. Subsequently, the TiO-coated 
samples were immediately immersed in four kinds of self-assembled phosphonic acid solutions (hexadecylphosphonic acid (HDPA, Sigma-Aldrich, Taipei, Taiwan), decylphosphonic acid (NDPA, Sigma-Aldrich, Taipei, Taiwan), 11-phosphonoundecanoic acid (PUA, Sigma-Aldrich, Taipei, Taiwan), or 16-phosphonohexadecanoic acid (PHA, Sigma-Aldrich, Taipei, Taiwan)) with a concentration of $1 \mathrm{mM}$ at $25^{\circ} \mathrm{C}$ for $24 \mathrm{~h}$. Hereafter, the investigated samples were rinsed twice with distilled water for 10 min and finally annealed at $120^{\circ} \mathrm{C}$ for $24 \mathrm{~h}$ in an oven. For easy classification, the TiO surface immersed with HDPA, NDPA, PUA, or PHA is denoted as HDPA-SAM/TiO, NDPA-SAM/TiO, PUA-SAM/TiO, and PHA-SAM/TiO, respectively. Moreover, the TiO surface without treatment is denoted as the control group. The chemical structure of the four kinds of self-assembled phosphonic acid solutions are shown in Figure 1.

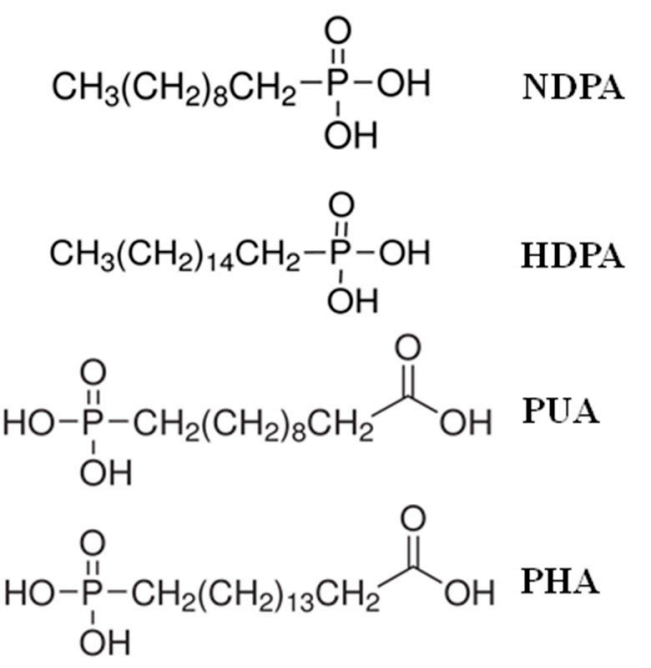

Figure 1. Chemical structures of the four kinds of self-assembled phosphonic acid solutions.

\subsection{Analysis of Surface Characteristics}

The field-emission scanning electron microscope (FE-SEM; JEOL JSM-6500F, Tokyo, Japan) accompanied by an energy-dispersive X-ray spectrometer (INCA, Abingdon, UK) was utilized to observe the surface morphology of the investigated samples under an operating voltage of $20 \mathrm{kV}$. The X-ray photoemission spectrometer with a monochromatic Al K $\alpha$ radiation source (XPS; MICROTECH MT-500, Manchester, UK) was employed to analyze the investigated samples under an incidence angle of $2^{\circ}$. For the detection of chemical compositions, a 15-nm diameter X-ray beam was used to obtain high-resolution scans. The spectrum was curve-fitted with a Gaussian-Lorentzian peak model before analysis.

\subsection{Wettability Evaluation}

Based on the sessile drop method, the wettability of the investigated samples was evaluated using phosphate buffer saline solution (Gibco $\mathrm{pH} 7.4$, Waltham, MA, USA) as a measurement substance (phosphate buffer saline solution is a nonpolar, unbondable, and low-viscosity liquid, and thus it is one of the adequate measurement substances used for wettability evaluation [28]). A droplet with a volume of $\approx 5 \mu \mathrm{L}$ was dropped on each investigated sample and the droplet was kept for $5 \mathrm{~s}$ through its own surface tension. Hereafter, the contact angle of the droplet on each investigated sample was measured using the contact angle goniometer with an optical subsystem (GBX DGD-DI, Drôme, France). An average of five drops per sample were used in the wettability evaluation. 


\subsection{Nano-Indentation Measurement}

The surface contact stiffness of the investigated samples was measured using nano-indentation with a diamond Berkovich indenter (Asmec-UNAT-M, Dresden, Germany) under a $10 \mathrm{mN}$ of load force with $5 \mathrm{~s}$ of dwell time. An average of three tests per sample was conducted in the study.

\subsection{Statistical Analysis}

The measured data are presented as mean \pm standard deviation. Student's $t$-test was applied to analyze the measured data. Measurements were considered to be statistically significant when the $p$-value was less than or equal to 0.05 .

\section{Results}

\subsection{Topography Characteristics}

Figure 2 shows the FE-SEM micrographs of the investigated samples. It is clear that the homogenous nanostructured TiO layer was deposited on the substrate surface (Figure 2a). After being immersed with four kinds of self-assembled phosphonic acid solutions, it was found that some aggregated island-like structures (as indicated by black arrows) were formed on the HDPA-SAM/TiO sample surface (Figure 2b). A similar topography feature can also be observed on the NDPA-SAM/TiO sample surface (Figure 2c). When the TiO sample was immersed with the PUA solution, the sample exhibited the uniform SAM surface as shown in Figure 2d. As the TiO sample was immersed in the PHA solution, the formation of larger aggregated island-like structures on the surface of the PHA-SAM/TiO sample took place (Figure 2e). The amount of the aggregated island-like structures in the PHA-SAM/TiO sample was more than that of the HDPA-SAM/TiO sample and NDPA-SAM/TiO sample.

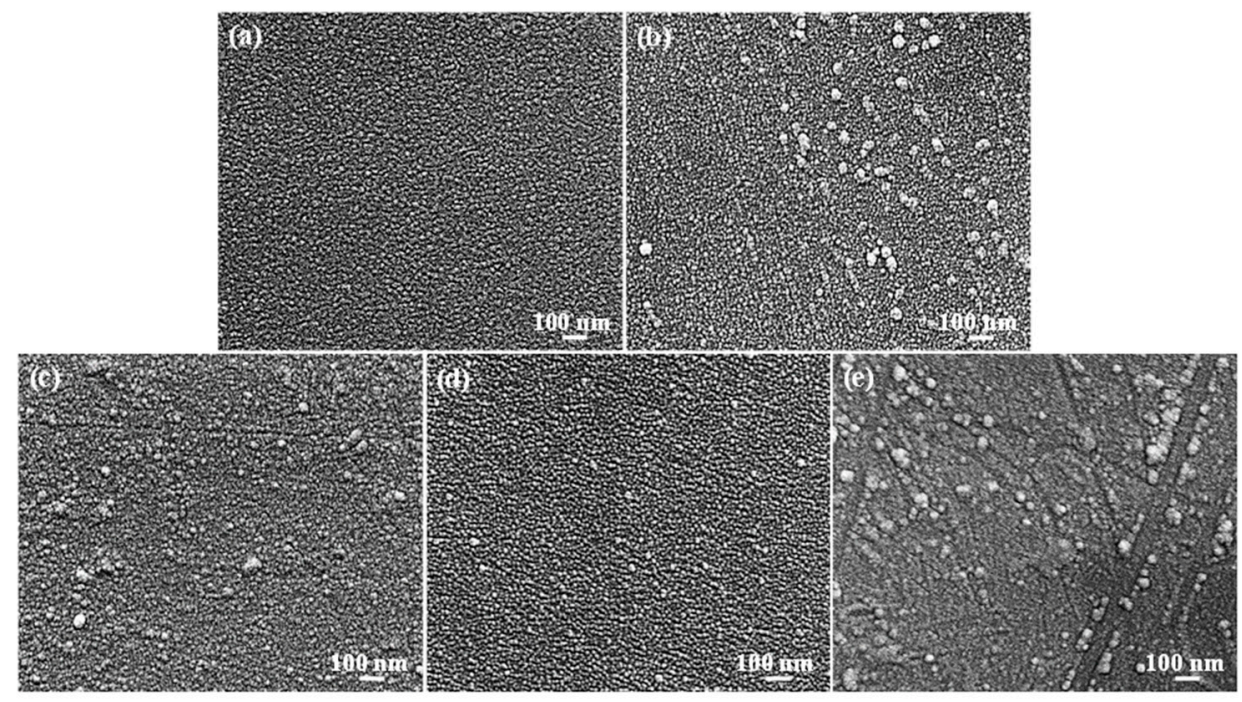

Figure 2. The SEM micrographs of investigated samples: (a) control TiO sample, (b) HDPA-SAM/TiO sample, (c) NDPA-SAM/TiO sample, (d) PUA-SAM/TiO sample, and (e) PHA-SAM/TiO sample.

\subsection{Surface Chemical Bonding States}

Figure 3a presents the high-resolution XPS survey spectrum of the TiO sample. It indicated that different chemical compositions of $\mathrm{O}, \mathrm{Ti}$, and $\mathrm{C}$ could be detected in the oxide layer using XPS. The $\mathrm{O} 1 \mathrm{~s}$, Ti $2 \mathrm{p}$, and $\mathrm{C} 1$ s peaks were observed at $\approx 530 \mathrm{eV}, \approx 458 \mathrm{eV}$, and $\approx 285 \mathrm{eV}$, respectively. The regional scan of the $\mathrm{O} 1 \mathrm{~s}$ peak taken from the oxide layer of the TiO sample is displayed in Figure 3b. The binding energy revealed that three characteristic components were mainly bonded on the surface layer after the plasma treatment. The three dominant peaks at $\approx 531 \mathrm{eV}, \approx 530 \mathrm{eV}$, and $\approx 529 \mathrm{eV}$ corresponded to $\mathrm{O}-\mathrm{Ti}, \mathrm{Ti}-\mathrm{O}_{2}$, and $\mathrm{O}-\mathrm{Ti}-\mathrm{O}$, respectively. The three dominant peaks proved that there was an oxide layer 
formation. It was also found that the concentration percentage of $\mathrm{O}$ and $\mathrm{Ti}$ in the surface layer of the $\mathrm{TiO}$ sample was around $32.4 \%$ and $10.1 \%$, respectively. The result demonstrated that the TiO film could be completely synthesized on the substrate surface. There was no presence of $\mathrm{P}$ in the surface layer of the TiO sample. However, additional peaks assigned to $P$ could be detected at $\approx 133 \mathrm{eV}$ (as indicated by black arrows) on the SAMs' coated surfaces, as illustrated in Figure 4. The concentration percentage of $\mathrm{P}$ in the surface layer of the HDPA-SAM/TiO, NDPA-SAM/TiO, PUA-SAM/TiO, and PHA-SAM/TiO samples was around $2.3 \%, 4.1 \%, 1.4 \%$, and $2.6 \%$, respectively. Figure 5 a displays the high-resolution XPS spectrum of $\mathrm{O} 1 \mathrm{~s}$ of the HDPA-SAM/TiO sample. Clearly, the bonding states of $\mathrm{P}=\mathrm{O}(\approx 532 \mathrm{eV})$, $\mathrm{P}-\mathrm{Ti}-\mathrm{O}(\approx 530 \mathrm{eV})$, and $\mathrm{O}-\mathrm{Ti}(\approx 529 \mathrm{eV})$ were detected in the surface layer using XPS. In the regional scan of the $\mathrm{P} 2 \mathrm{p}$ peak (Figure $5 \mathrm{~b}$ ), the binding energy indicated that the component characteristics of $\mathrm{P}-\mathrm{O}$ $(\approx 133 \mathrm{eV})$ and $\mathrm{P}=\mathrm{O}(\approx 132 \mathrm{eV})$ were bonded in the surface layer. A similar tendency of the bonding states could also be found in the surface layer of the NDPA-SAM/TiO, PUA-SAM/TiO, and PHA-SAM/TiO samples. Accordingly, the XPS results demonstrated that the SAMs of phosphonate could be formed on the surface of the TiO layer through Ti-O-P linkages.
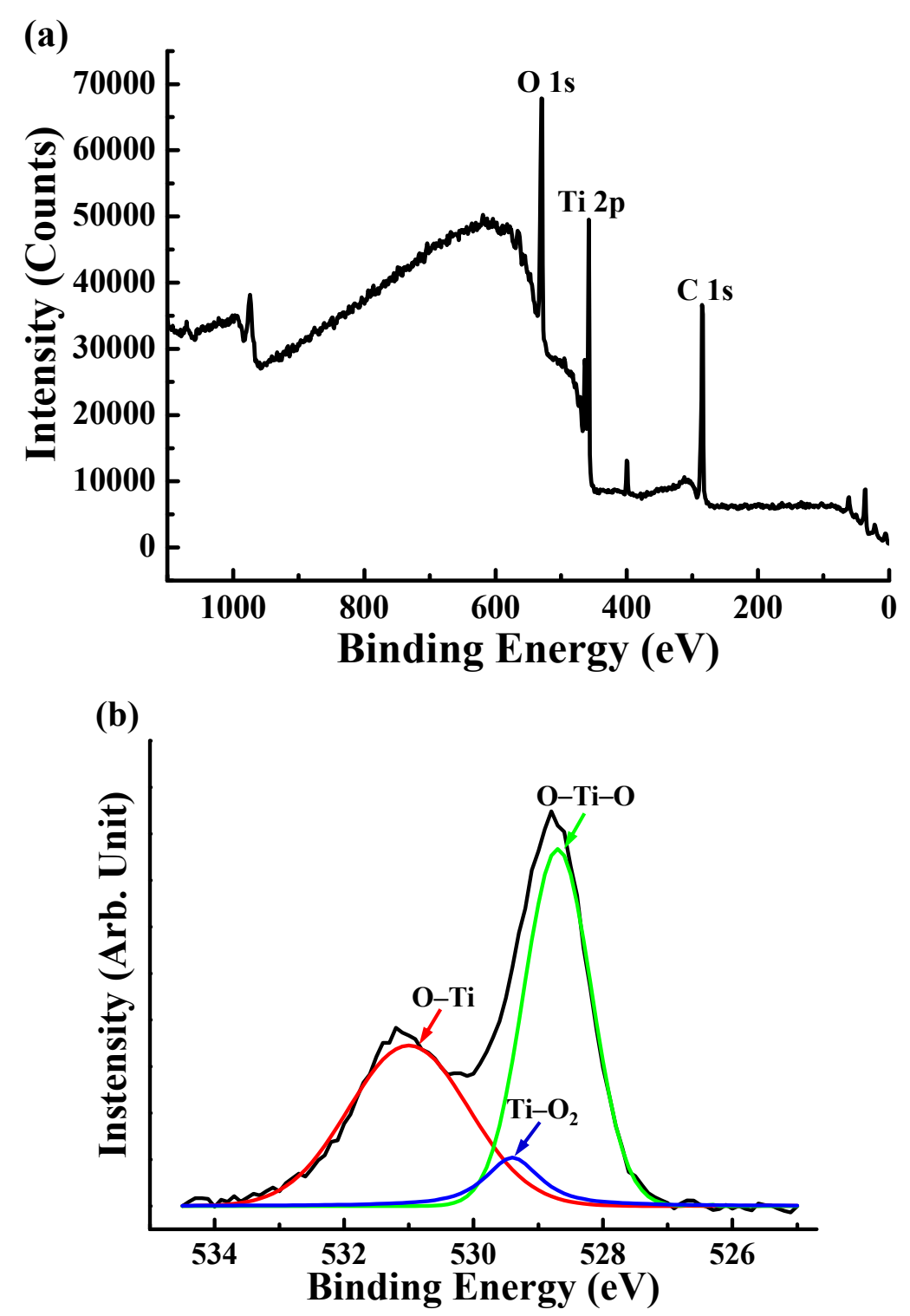

Figure 3. (a) The high-resolution XPS survey spectrum of the TiO sample and (b) the regional scans of $\mathrm{O} 1 \mathrm{~s}$ peaks taken from the $\mathrm{TiO}$ sample surface. 

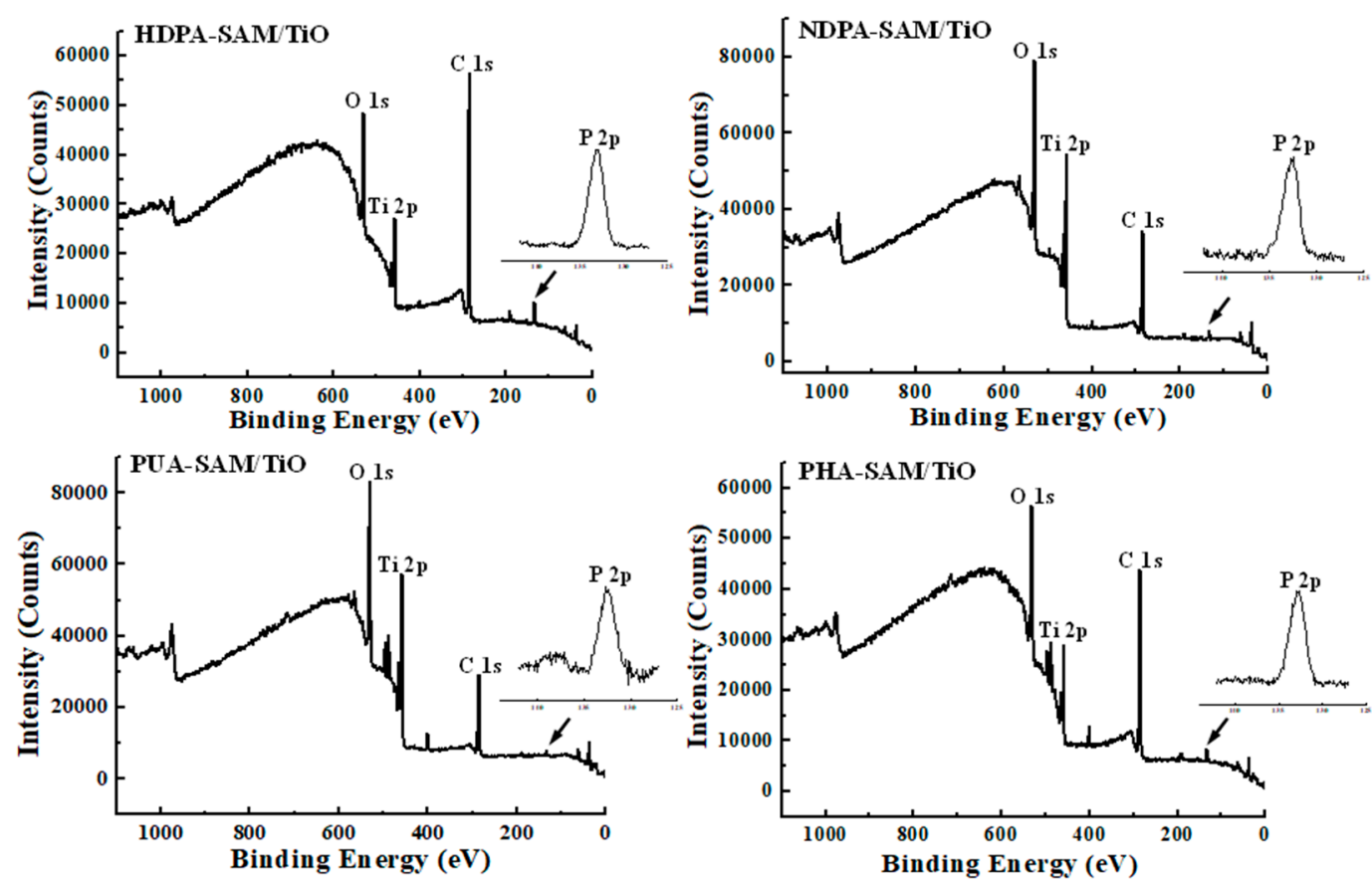

Figure 4. The high-resolution XPS survey spectra of the SAMs-coated samples.
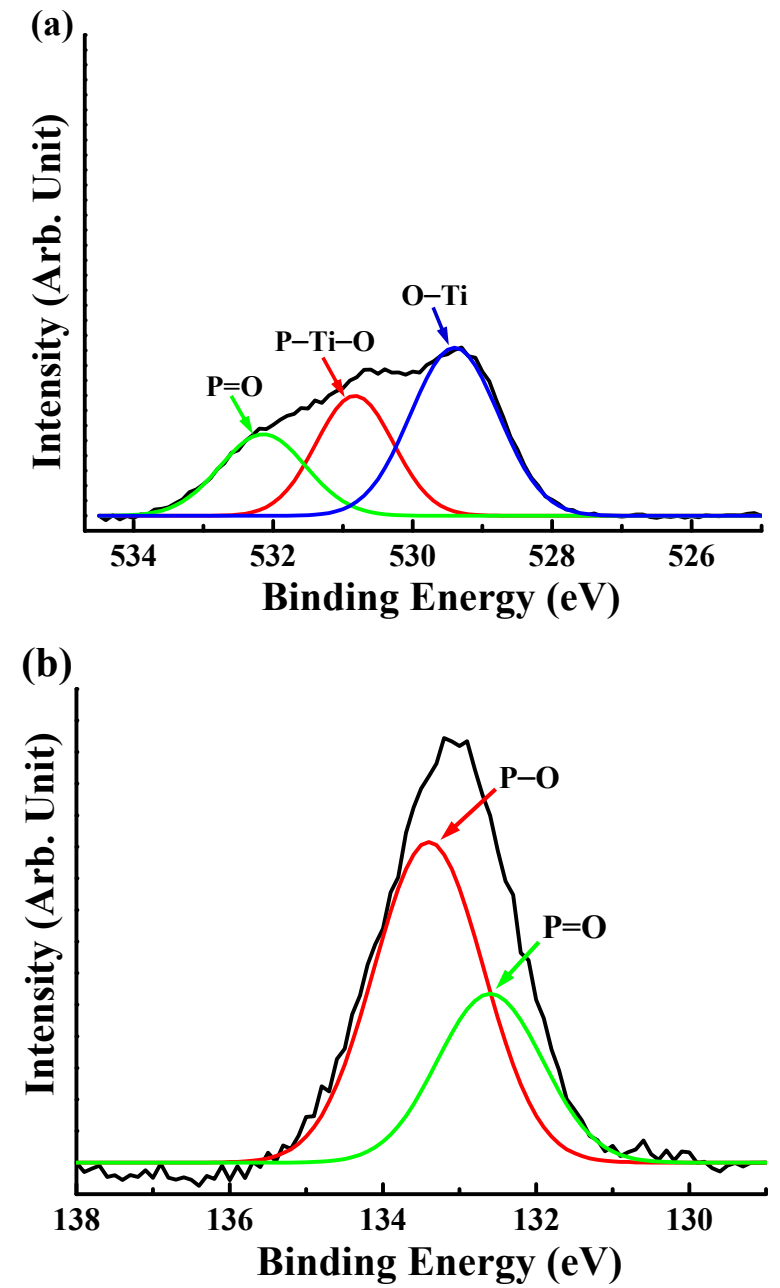

Figure 5. (a) the high-resolution XPS spectrum of $\mathrm{O} 1 \mathrm{~s}$ of the HDPA-SAM/TiO sample and (b) the regional scans of $\mathrm{P} 2 \mathrm{p}$ peaks taken from the HDPA-SAM/TiO sample surface. 


\subsection{Characterization of the Surface Wettability}

Figure 6 gives the average contact angle results of the investigated samples. According to the optical subsystem measurement, it was found that the average contact angles of the control, HDPA-SAM/TiO, NDPA-SAM/TiO, PUA-SAM/TiO, and PHA-SAM/TiO samples were $81.7 \pm 0.9^{\circ}$, $83.3 \pm 0.9^{\circ}, 90.3 \pm 0.4^{\circ}, 68.8 \pm 0.7^{\circ}$, and $78.9 \pm 1.2^{\circ}$, respectively $\left({ }^{*} p<0.05\right)$. Evidently, it indicated that the NDPA-SAM/TiO sample exhibited surface hydrophobicity since its contact angle was slightly larger than $90^{\circ}$. Hydrophobic surfaces are usually defined as having water contact angles greater than or equal to $90^{\circ}$. Contrarily, the water contact angle of a hydrophilic surface is typically less than $90^{\circ}$. Thus, the control, HDPA-SAM/TiO, PUA-SAM/TiO, and PHA-SAM/TiO samples possessed hydrophilic surfaces. However, the PUA-SAM/TiO sample had the best hydrophilic surface as compared to the other investigated samples.

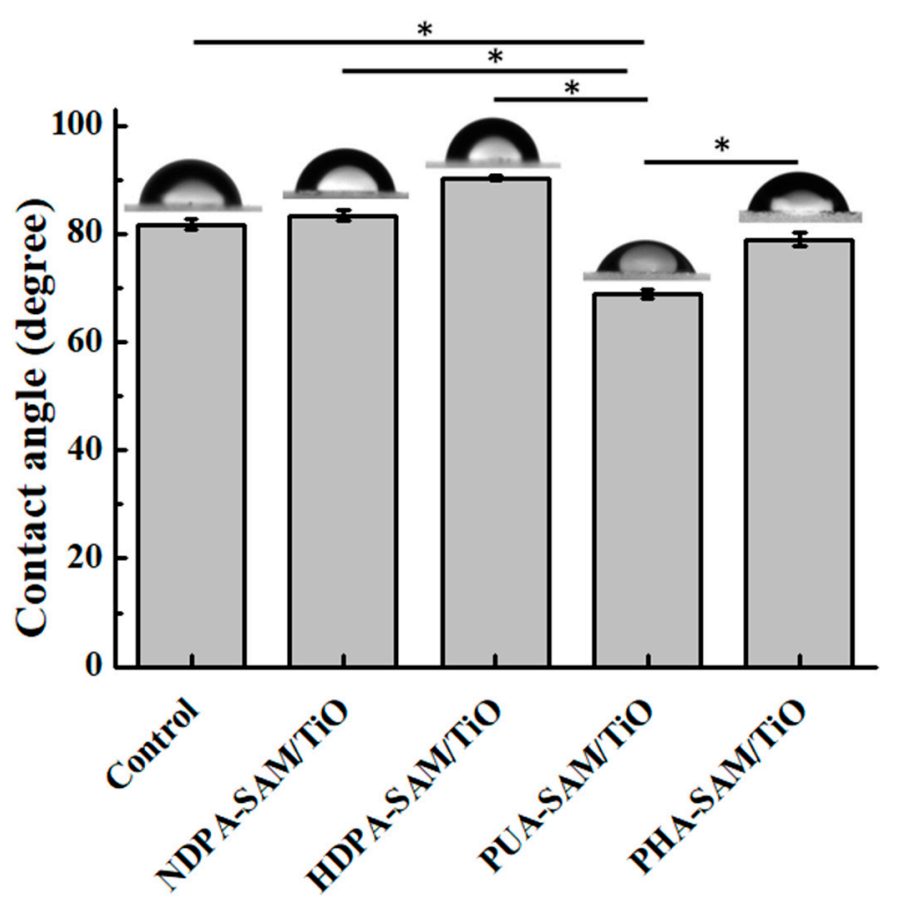

Figure 6. The average contact angle results of the investigated samples $\left({ }^{*} p<0.05\right)$.

\subsection{Variation of the Surface Contact Stiffness}

Figure 7 depicts the surface contact stiffness results of the investigated samples after nano-indentation. As shown, the surface contact stiffness slightly increased with increasing penetration depth. Based on the nano-indentation measurement, it was found that the average surface contact stiffness of the control, HDPA-SAM/TiO, NDPA-SAM/TiO, PUA-SAM/TiO, and PHA-SAM/TiO samples were approximately $20.7 \pm 1.2 \mathrm{mN} / \mu \mathrm{m}, 13.8 \pm 0.7 \mathrm{mN} / \mu \mathrm{m}, 12.5 \pm 1.1 \mathrm{mN} / \mu \mathrm{m}, 12.1 \pm 0.8 \mathrm{mN} / \mu \mathrm{m}$, and $11.7 \pm 0.5 \mathrm{mN} / \mu \mathrm{m}$, respectively $(* p<0.05)$. The control TiO sample exhibited the maximum surface contact stiffness in comparison to the SAMs-coated samples. However, there was no significant difference between the SAMs-coated samples in terms of the surface contact stiffness. 


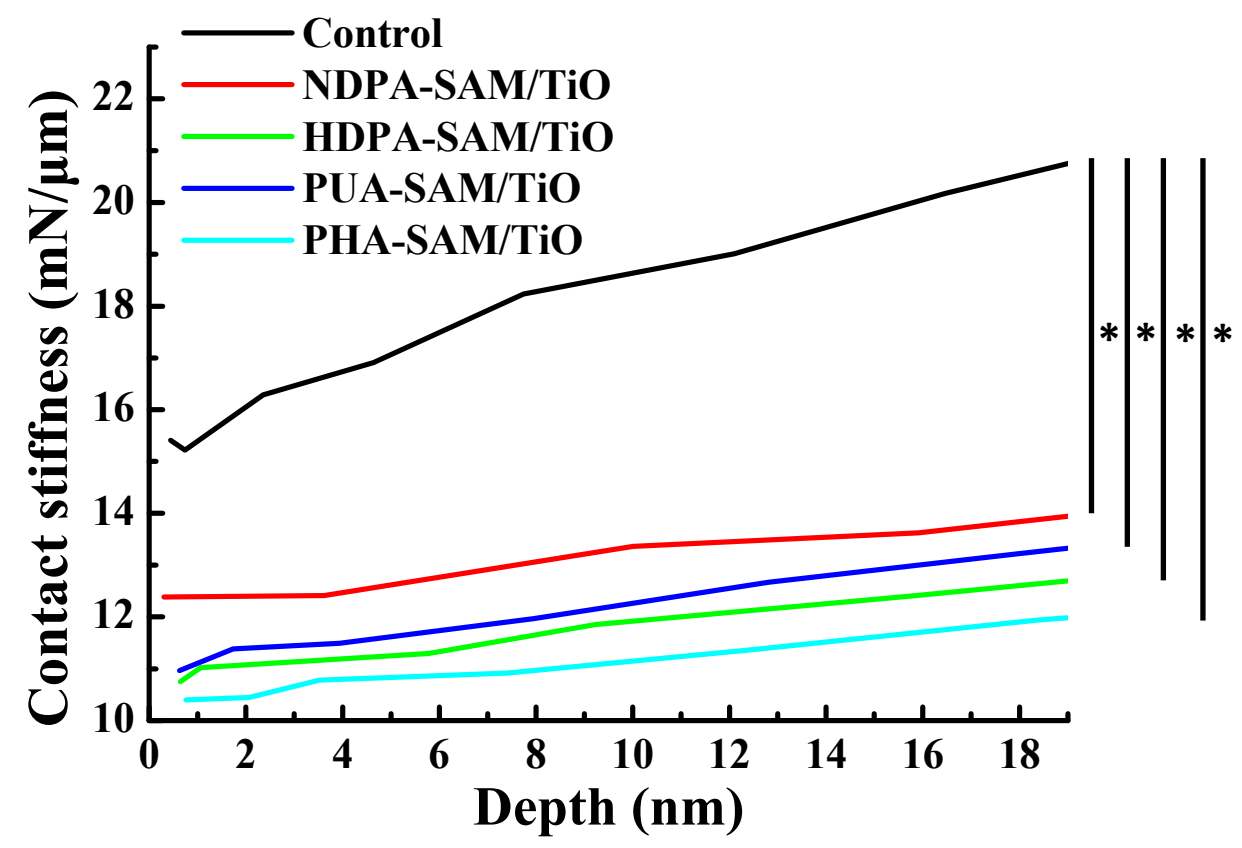

Figure 7. The surface contact stiffness results of the investigated samples after nano-indentation $(* p<0.05)$.

\section{Discussion}

In this study, four kinds of self-assembled phosphonic acid solutions were used to coat the SAMs of phosphonate on the TiO layers. However, it was clear that there was the presence of larger aggregated island-like structures on the surfaces of the HDPA-SAM/TiO, NDPA-SAM/TiO, and PHA-SAM/TiO samples, as shown in Figure 2. The amount of the aggregated island-like structures in the PHA-SAM/TiO sample was more than that of the HDPA-SAM/TiO sample and NDPA-SAM/TiO sample. The formation of this feature could be attributed to the higher molecular weights in HDPA, NDPA, and PHA, which induced more organophosphorus compounds to bond with the $\mathrm{O}$ atoms. Typically, there are two organophosphorus compounds $\mathrm{C}-\mathrm{PO}(\mathrm{OH})_{2}$ or $\mathrm{C}-\mathrm{PO}(\mathrm{OA})_{2}$ groups (where $\mathrm{A}=$ alkyl, aryl) contained in the phosphonic acids $[29,30]$. They easily bond with $\mathrm{O}$ in the oxide layer to form the SAMs via Ti-O-P linkages [26]. Therefore, the SAMs-coated samples with a higher molecular weight caused the formation of non-uniform layered interfaces. Similar topography characteristics can also be found in a report by Diebold and Clarke [31]. On the contrary, the PUA-SAM/TiO sample had the great potential to form a uniform SAM surface. Moreover, chemical bonding states of the control and SAMs-coated samples were further analyzed using XPS. Based on the XPS results, the formation of a homogenous nanostructured $\mathrm{TiO}$ layer on the substrate surface can be fabricated using an oxygen plasma treatment $[13,32]$. An exothermic plasma reaction generates some of $\mathrm{O}_{2}, \mathrm{O}^{*}$, and $\mathrm{O}^{2-}$ species or radicals to fix at lattice or interstitial sites [13]. This reaction offers a key driving force for the transport of $\mathrm{O}$ species to form the $\mathrm{TiO} / \mathrm{Ti}$ or $\mathrm{TiO}_{2} / \mathrm{Ti}$ [33]. There was no detectable $\mathrm{P}$ at its corresponding binding energy, which demonstrated that there was no organic compound contaminants on the surface of the control TiO sample. After being coated with different SAMs, the binding energy of $\mathrm{O} 1 \mathrm{~s}$ indicated that the component characteristics of $\mathrm{P}=\mathrm{O}(\approx 532 \mathrm{eV}), \mathrm{P}-\mathrm{Ti}-\mathrm{O}(\approx 530 \mathrm{eV})$, and $\mathrm{O}-\mathrm{Ti}(\approx 529 \mathrm{eV})$ were bonded in the surface layer. The three $\mathrm{O} 1 \mathrm{~s}$ signals confirmed the formation of the bisphosphonate monolayer on the SAMs-coated samples [34,35]. Meanwhile the use of the C 1s signal for quantification purposes was not considered because it is difficult to accurately determine the uncertainty of $C$ on the Ti surface [36]. Furthermore, Zdziennicka et al. [37] indicated that the hydrophilic-hydrophobic balance of the investigated surface covered by various substances depends on the orientation of the surface molecules and density of the surface layer. For surface modification of the TiO surface, phosphonic acids of different chain lengths and terminal functional groups were chosen: (i) $\mathrm{CH}_{3}$ as a 
hydrophobic and non-reactive group (HDPA-SAM/TiO and NDPA-SAM/TiO samples) and (ii) $\mathrm{COOH}$ as a hydrophilic and reactive group (PUA-SAM/TiO and PHA-SAM/TiO samples). Thus, their terminal functional groups $\left(\mathrm{CH}_{3} / \mathrm{COOH}\right)$ will determine the surface properties of the modified substrates. According to the results (Figure 6), surfaces with $\mathrm{CH}_{3}$-terminated SAMs were slightly hydrophobic and surfaces with $\mathrm{COOH}$-terminated SAMs were more hydrophilic compared with the $\mathrm{TiO}$ surface. The results for these investigated SAMs were quite reasonable. However, surfaces with $\mathrm{CH}_{3}$-terminated SAMs should be more hydrophobic than the TiO surface if their SAMs are compact and homogeneous. In the case of stable, compact SAM where alkyl chains are connected via van der Waals interactions, only a terminal functional group is in direct contact with the solvent drop. Therefore, the presence of a $\mathrm{COOH}$-terminated group on the compact and homogeneous SAM surface (PUA-SAM/TiO sample), which contributes to the reactive group of hydrophilic, thus enhances the surface wettability [26]. It is well known that a surface with a higher wettability property promotes protein adsorption and improves surface biocompatibility [38,39]. In addition, the contact stiffness values did differ significantly between TiO and SAMs-coated surfaces (Figure 7). The SAMs-coated surfaces exhibited a decrease in stiffness as a consequence of the formation of the bisphosphonate monolayer, which could disperse stress concentration, hence decreasing the stress shielding effect [40]. The formation of stress shielding can cause a loss of bone tissue around the implant and poor osseointegration [41-43]. Accordingly, the PUA-SAM/TiO sample is believed to prevent the stress shielding effect and possess better in vivo bone regeneration ability in comparison to the control sample and the other SAMs-coated samples. However, further studies should be performed to provide additional information concerning the biocompatibility, cell morphology, and bone healing in the presence of a PUA-SAM/TiO sample.

\section{Conclusions}

The homogenous nanostructured $\mathrm{TiO}$ layer could be deposited on the glass substrate surface by means of the plasma oxidation method. After being immersed with four kinds of phosphonic acid solutions, the SAMs of phosphonate could be tightly bonded with the TiO layer through Ti-O-P linkages. The PUA-SAM/TiO sample exhibited a uniform surface topography, higher wettability, and low surface contact stiffness compared with other SAMs-coated samples. Therefore, the formation of SAMs of phosphonate onto $\mathrm{TiO}$ oxide layer provides an effective method to anchor bone-promoting bisphosphonates from a phosphonic acid solution onto biomedical Ti implants with a facilitated bone regeneration capacity. It has great potential for being a biofunctional surface for biomedical $\mathrm{Ti}$ implant applications.

Author Contributions: Investigation and Writing_original draft, W.-C.L.; Writing_original draft, T.-S.H.; Methodology, Y.-C.C.; Data curation, Y.-T.H., P.-C.C., and F.-T.P.; Supervision, C.J.W.; Validation, M.R.; Writing-review \& editing, C.-C.H. and M.-S.H. All authors have read and agreed to the published version of the manuscript.

Funding: This research received no external funding.

Conflicts of Interest: The authors report no conflict of interest in this work.

\section{References}

1. Naseri, R.; Kadkhodayan, M.; Shariati, M. Static mechanical properties and ductility of biomedical ultrafine-grained commercially pure titanium produced by ECAP process. Trans. Nonferr. Metal. Soc. 2017, 27, 1964-1975. [CrossRef]

2. Nie, D.M.; Lu, Z; Zhang, K.F. Grain Size Effect of Commercial Pure Titanium Foils on Mechanical Properties, Fracture Behaviors and Constitutive Models. J. Mater. Eng. Perform. 2017, 26, 1283-1292.

3. Sabat, R.K.; Sahoo, S.K.; Bishoyi, B.D.; Bibhanshu, N.; Suwas, S. Improvement in mechanical properties of commercially pure titanium through reverse rolling. Philos. Mag. Lett. 2017, 97, 273-279. [CrossRef]

4. Barjaktarevic, D.R.; Dimic, I.D.; Cvijovic-Alagic, I.L.; Veljovic, D.N.; Rakin, M.P. Corrosion Resistance of High Pressure Torsion Obtained Commercially Pure Titanium in Acidic Solution. Tehnički Vjesnik 2017, 24, 1689-1695. 
5. Chittaranjan, B.; Murthy, B.S.; Ravindranath, T. An Evaluation of Biocompatibility of Indigenously Produced Pure Titanium: An Experimental Study in Rabbits. J. Oral Implantol. 2012, 38, 575-580. [CrossRef] [PubMed]

6. Brizuela, A.; Herrero-Climent, M.; Rios-Carrasco, E.; Rios-Santos, J.V.; Perez, R.A.; Manero, J.M.; Mur, J.G. Influence of the Elastic Modulus on the Osseointegration of Dental Implants. Materials 2019, 12, 980. [CrossRef]

7. Shibata, Y.; Tanimoto, Y.; Maruyama, N.; Nagakura, M. A review of improved fixation methods for dental implants. Part II: Biomechanical integrity at bone-implant interface. J. Prosthodont. Res. 2015, 59, 84-95. [CrossRef]

8. Tang, D.; Yang, L.Y.; Ou, K.L.; Oreffo, R.O.C. Repositioning Titanium: An In Vitro Evaluation of Laser-Generated Microporous, Microrough Titanium Templates As a Potential Bridging Interface for Enhanced Osseointegration and Durability of Implants. Front. Bioeng. Biotechnol. 2017, 5, 77. [CrossRef]

9. Tsai, M.H.; Haung, C.F.; Shyu, S.S.; Chou, Y.R.; Lin, M.H.; Peng, P.W.; Ou, K.L.; Yu, C.H. Surface modification induced phase transformation and structure variation on the rapidly solidified recast layer of titanium. Mater. Charact. 2015, 106, 463-469. [CrossRef]

10. Smeets, R.; Stadlinger, B.; Schwarz, F.; Beck-Broichsitter, B.; Jung, O.; Precht, C.; Kloss, F.; Grobe, A.; Heiland, M.; Ebker, T. Impact of Dental Implant Surface Modifications on Osseointegration. Biomed. Res. Int. 2016, 2016, 6285620. [CrossRef]

11. Giannasi, C.; Pagni, G.; Polenghi, C.; Niada, S.; Manfredi, B.; Brini, A.T.; Rasperini, G. Impact of Dental Implant Surface Modifications on Adhesion and Proliferation of Primary Human Gingival Keratinocytes and Progenitor Cells. Int. J. Periodontics Restor. Dent. 2018, 38, 127-135. [CrossRef]

12. Hou, P.J.; Ou, K.L.; Wang, C.C.; Huang, C.F.; Ruslin, M.; Sugiatno, E.; Yang, T.S.; Chou, H.H. Hybrid micro/nanostructural surface offering improved stress distribution and enhanced osseointegration properties of the biomedical titanium implant. J. Mech. Behav. Biomed. 2018, 79, 173-180. [CrossRef]

13. Chiang, H.J.; Chou, H.H.; Ou, K.L.; Sugiatno, E.; Ruslin, M.; Waris, R.A.; Huang, C.F.; Liu, C.M.; Peng, P.W. Evaluation of Surface Characteristics and Hemocompatibility on the Oxygen Plasma-Modified Biomedical Titanium. Metals (Basel) 2018, 8, 513. [CrossRef]

14. Wu, C.M.; Liu, C.M.; Ou, K.L.; Chiang, H.J.; Sugiatno, E.; Wu, C.H.; Yen, H.J.; Chou, H.H. Nanostructured titanium dioxide layer combined with reactive functional groups as a promising biofunctional surface for biomedical applications. Ceram. Int. 2019, 45, 9712-9718. [CrossRef]

15. Le Guehennec, L.; Soueidan, A.; Layrolle, P.; Amouriq, Y. Surface treatments of titanium dental implants for rapid osseointegration. Dent. Mater. 2007, 23, 844-854. [CrossRef]

16. Fousova, M.; Vojtech, D.; Jablonska, E.; Fojt, J.; Lipov, J. Novel Approach in the Use of Plasma Spray: Preparation of Bulk Titanium for Bone Augmentations. Materials 2017, 10, 987. [CrossRef]

17. Schwartz, Z.; Raz, P.; Zhao, G.; Barak, Y.; Tauber, M.; Yao, H.; Boyan, B.D. Effect of micrometer-scale roughness of the surface of Ti6Al4V pedicle screws in vitro and in vivo. J. Bone Jt. Surg. Am. 2008, 90, 2485-2498. [CrossRef]

18. Ghumatkar, A.; Budhe, S.; Sekhar, R.; Banea, M.D.; de Barros, S. Influence of Adherend Surface Roughness on the Adhesive Bond Strength. Lat. Am. J. Solids Struct. 2016, 13, 2356-2370. [CrossRef]

19. Cuellar-Flores, M.; Acosta-Torres, L.S.; Martinez-Alvarez, O.; Sanchez-Trocino, B.; de la Fuente-Hernandez, J.; Garcia-Garduno, R.; Garcia-Contreras, R. Effects of alkaline treatment for fibroblastic adhesion on titanium. Dent. Res. J. (Isfahan) 2016, 13, 473-477.

20. El-Wassefy, N.A.; Reicha, F.M.; Aref, N.S. Electro-chemical deposition of nano hydroxyapatite-zinc coating on titanium metal substrate. Int. J. Implant. Dent. 2017, 3, 39. [CrossRef]

21. Siriviriyanun, A.; Imae, T. Solvo-affinity property of glass surfaces modified by self-assembled monolayers of organic and/or inorganic chemicals. J. Taiwan Inst. Chem. Eng. 2014, 45, 3090-3098. [CrossRef]

22. Will, J.; Hou, Y.; Scheiner, S.; Pinkert, U.; Hermes, I.M.; Weber, S.A.L.; Hirsch, A.; Halik, M.; Brabec, C.; Unruh, T. Evidence of Tailoring the Interfacial Chemical Composition in Normal Structure Hybrid Organohalide Perovskites by a Self-Assembled Monolayer. ACS Appl. Mater. Interfaces 2018, 10, 5511-5518. [CrossRef] [PubMed]

23. Kohale, S.C.; Pratihar, S.; Hase, W.L. Chemical Dynamics Simulations of Thermal Desorption of Protonated Dialanine from a Perfluorinated Self-Assembled Monolayer Surface. J. Phys. Chem. Lett. 2018, 9, 1554-1560. [CrossRef] [PubMed] 
24. Freitas, S.C.; Correa-Uribe, A.; Martins, M.C.L.; Pelaez-Vargas, A. Self-Assembled Monolayers for Dental Implants. Int. J. Dent. 2018, 2018, 4395460. [CrossRef]

25. Han, X.; Sun, X.; He, T.; Sun, S. Formation of highly stable self-assembled alkyl phosphonic acid monolayers for the functionalization of titanium surfaces and protein patterning. Langmuir 2015, 31, 140-148. [CrossRef]

26. Rojo, L.; Gharibi, B.; McLister, R.; Meenan, B.J.; Deb, S. Self-assembled monolayers of alendronate on Ti6Al4V alloy surfaces enhance osteogenesis in mesenchymal stem cells. Sci. Rep. 2016, 6, 30548. [CrossRef]

27. Huang, C.F.; Cheng, H.C.; Liu, C.M.; Chen, C.C.; Ou, K.L. Microstructure and phase transition of biocompatible titanium oxide film on titanium by plasma discharging. J. Alloys Compd. 2009, 476, 683-688. [CrossRef]

28. Silverio, V.; Canane, P.A.G.; Cardos, S. Surface wettability and stability of chemically modified silicon, glass and polymeric surfaces via room temperature chemical vapor deposition. Colloids Surf. A 2019, 570, 210-217. [CrossRef]

29. Zhao, R.H.; Rupper, P.; Gaan, S. Recent Development in Phosphonic Acid-Based Organic Coatings on Aluminum. Coatings 2017, 7, 133. [CrossRef]

30. Demkowicz, S.; Rachon, J.; Dasko, M.; Kozak, W. Selected organophosphorus compounds with biological activity. Applications in medicine. RSC Adv. 2016, 6, 7101-7112. [CrossRef]

31. Diebold, R.M.; Clarke, D.R. Smooth, aggregate-free self-assembled monolayer deposition of silane coupling agents on silicon dioxide. Langmuir 2012, 28, 15513-15520. [CrossRef] [PubMed]

32. Ou, K.L.; Shih, Y.H.; Huang, C.F.; Chen, C.C.; Liu, C.M. Preparation of bioactive amorphous-like titanium oxide layer on titanium by plasma oxidation treatment. Appl. Surf. Sci. 2008, 255, 2046-2051. [CrossRef]

33. Gottlicher, M.; Rohnke, M.; Kunz, A.; Thomas, J.; Henning, R.A.; Leichtweiss, T.; Gemming, T.; Janek, J. Anodization of titanium in radio frequency oxygen discharge-Microstructure, kinetics \& transport mechanism. Solid State Ion. 2016, 290, 130-139.

34. Hofer, R.; Textor, M.; Spencer, N.D. Alkyl phosphate monolayers, self-assembled from aqueous solution onto metal oxide surfaces. Langmuir 2001, 17, 4014-4020. [CrossRef]

35. Metoki, N.; Liu, L.; Beilis, E.; Eliaz, N.; Mandler, D. Preparation and Characterization of Alkylphosphonic Acid Self-Assembled Mono layers on Titanium Alloy by Chemisorption and Electrochemical Deposition. Langmuir 2014, 30, 6791-6799. [CrossRef]

36. Kang, B.S.; Sul, Y.T.; Oh, S.J.; Lee, H.J.; Albrektsson, T. XPS, AES and SEM analysis of recent dental implants. Acta Biomater 2009, 5, 2222-2229. [CrossRef]

37. Zdziennicka, A.; Szymczyk, K.; Krawczyk, J.; Janczuk, B. Components and parameters of solid/surfactant layer surface tension. Colloids Surf. A 2017, 522, 461-469. [CrossRef]

38. Huang, M.T.; Juan, P.K.; Chen, S.Y.; Wu, C.J.; Wen, S.C.; Cho, Y.C.; Huang, M.S.; Chou, H.H.; Ou, K.L. The potential of the three-dimensional printed titanium mesh implant for cranioplasty surgery applications: Biomechanical behaviors and surface properties. Mater. Sci. Eng. C Mater. 2019, 97, 412-419. [CrossRef]

39. Lee, F.P.; Wang, D.Y.; Chen, L.K.; Kung, C.M.; Wu, Y.C.; Ou, K.L.; Yu, C.H. Antibacterial nanostructured composite films for biomedical applications: Microstructural characteristics, biocompatibility, and antibacterial mechanisms. Biofouling 2013, 29, 295-305. [CrossRef]

40. Cattalini, J.P.; Boccaccini, A.R.; Lucangioli, S.; Mourino, V. Bisphosphonate-based strategies for bone tissue engineering and orthopedic implants. Tissue Eng. B Rev. 2012, 18, 323-340. [CrossRef]

41. Apostu, D.; Lucaciu, O.; Berce, C.; Lucaciu, D.; Cosma, D. Current methods of preventing aseptic loosening and improving osseointegration of titanium implants in cementless total hip arthroplasty: A review. J. Int. Med. Res. 2018, 46, 2104-2119. [CrossRef]

42. Noyama, Y.; Miura, T.; Ishimoto, T.; Itaya, T.; Niinomi, M.; Nakano, T. Bone Loss and Reduced Bone Quality of the Human Femur after Total Hip Arthroplasty under Stress-Shielding Effects by Titanium-Based Implant. Mater. Trans. 2012, 53, 565-570. [CrossRef]

43. Prochor, P.; Sajewicz, E. The Influence of Geometry of Implants for Direct Skeletal Attachment of Limb Prosthesis on Rehabilitation Program and Stress-Shielding Intensity. BioMed Res. Int. 2019, 2019, 6067952. [CrossRef] [PubMed]

(C) 2020 by the authors. Licensee MDPI, Basel, Switzerland. This article is an open access article distributed under the terms and conditions of the Creative Commons Attribution (CC BY) license (http://creativecommons.org/licenses/by/4.0/). 